\title{
NON-INVASIVE TREATMENT OF DEMINERALIZED ENAMEL BY EGGSHELL POWDER, BIOACTIVE GLASS, AND CASEIN: COMPARATIVE STUDY
}

\author{
Ramy Abdallah Abdelrahim*, Ibrahim Eldsoki Basha** and Hamed Ibrahim Elkadi**
}

\begin{abstract}
Introduction: Non-invasive treatment protocol of demineralized enamel lesions as a more conservative procedure by different remineralizing agents would bring a major approach in the clinical management of these enamel defects.
\end{abstract}

Aim: The present study was aimed to investigate in-situ remineralization of the demineralized enamel surface, by treatment with different remineralizing agents and stored in artificial saliva with neutral $\mathrm{pH}$, at $37^{\circ} \mathrm{C}$ for 21 days.

Materials and Method: We investigated the morphology, and chemical composition of the demineralized and remineralized enamel surface, which treated with Chicken Eggshell powder solution (CESPS), Bioactive Glass (BAG), and Casein phosphopeptide-amorphous calcium phosphate (CPP-ACP) as remineralizing agent twice daily and stored in artificial saliva for 21 days. The surface morphology, as well as the chemical composition of the remineralized enamel samples, were studied by scanning electron microscopy (SEM) coupled with energy dispersive X-ray (EDX) spectrometry.

Results: CESPS resulted in higher and significant remineralization results when comparing with BAG alone or in combination with it as well as showed a significant effect when compared with CPP-ACP.

Conclusion: CESPS, BAG, and CPP-ACP can use as a non-invasive treatment of early carious enamel lesions.

KEY WORDS: Bioactive glass, Casein, Demineralized, Enamel, Eggshell

\section{INTRODUCTION}

Enamel is the outer layer of the tooth crown and considered the hardest human tissue, even harder than bone ${ }^{(1,2)}$. It is essentially composed of an inorganic apatite structure; known as hydroxyapatite (HA), which is calcium-phosphate mineral complex $\left(\mathrm{Ca}_{10}\left[\mathrm{PO}_{4}\right] 6[\mathrm{OH}]_{2}\right)^{(2)}$. Additionally, enamel made up of organic components like lipids and proteins, as well as, water ${ }^{(2,3)}$. 
Dental caries initiated as a result of demineralization - remineralization imbalance which is a cyclic process and considers the utmost importance in caries prevention and/or treatment ${ }^{(4,5)}$. The ratio between cyclic demineralization and remineralization process is the key that determines the progression or prevention of tooth caries ${ }^{(4)}$. Fortunately, the early stage of enamel demineralization is a reversible process ${ }^{(5,6)}$.

Demineralization process of enamel known as dissolution and finally loss of carbonated hydroxyapatite minerals from tooth structure due to $\mathrm{pH}$ decline of the oral environment ${ }^{(6,7)}$. Highly consumption of acidic beverage as well as acids produced by food fermentation by oral cariogenic bacteria leads to an oral environment with a lower level of mineral ion content in comparing to the enamel mineral and demineralization phase initiated ${ }^{(6-8)}$.

Furthermore, the existence of the demineralization phase for a long period may lead to excessive mineral loss and finally enamel cavitation. The demineralization process of enamel can be reversed when oral $\mathrm{pH}$ rise, resulting in mineral deposition back to the enamel ${ }^{(6,8,9)}$.

Remineralization process can be defined as the process whereby calcium $(\mathrm{Ca})$ and phosphate $\left(\mathrm{HPO}_{4}\right)$ ions are supplied from an external source to the tooth enamel to push for ion deposition into mineral vacancies in demineralized enamel to fruitage net crystalline mineral gain ${ }^{(10)}$. It was reported that various bioactive agents like bioactive glass (BAG), and casein phosphopeptideamorphous calcium phosphate (CPP-ACP), was successful in the treatment of demineralized enamel via $\mathrm{Ca}$ and $\mathrm{HPO}_{4}$ deposition ${ }^{(11-13)}$.

$\mathrm{BAG}$ is a bioceramic material that can release calcium, sodium $(\mathrm{Na})$, silicate, and $\mathrm{HPO}_{4}$ ions, also, it capable of forming a calcium-phosphate "hydroxyapatite" when exposed to the oral fluid which precipitates on the tooth surface and helps in enamel remineralization ${ }^{(14)}$. Recently, "NovaMin" toothpaste was introduced in the dental market based on this formulation ${ }^{(15)}$.
CPP-ACP is a complex of casein phosphopeptide (CPP) which is "milk-derived protein" and amorphous calcium phosphate (ACP). Casein phosphopeptide is the charged region of this complex that can bind to enamel minerals and used to stabilize the clusters of amorphous calcium phosphate which can precipitate on the enamel surface to elevate $\mathrm{Ca}$ levels in the plaque fluid to help in its remineralization ${ }^{(16)}$. This formulation was utilized in the dental market to produce toothpaste, chewing gum, and mouth rinses ${ }^{(14,17)}$.

Additionally, it was found that Chicken eggshell powder (CESP) has higher Ca content and can remineralize the demineralized enamel, as it contains approximately 39\% (w/w) elemental Ca with a bio-accessibility as high as from calcium carbonate $\left(\mathrm{CaCO}_{3}\right)^{(18)}$.

The non-invasive treatment of demineralized enamel by various remineralizing agents has major importance in conservative restorative management and researchers ${ }^{(18-21)}$

Therefore, this in-vitro study aimed to evaluate the remineralization effect of various remineralizing agents containing $\mathrm{Ca}$ and/or $\mathrm{HPO}_{4}$ ions.

\section{MATERIALS AND METHODS}

\section{Preparation of Chicken Eggshell Powder:}

CESP was prepared via calcination process to obtain pure, pathogenic free, and highly alkaline powder ${ }^{(22)}$, according to the World Property intellectual organization protocol (WO/2004/105912: Method of CESP production) ${ }^{(23)}$. On calcination; the CESP which normally contains about $95 \%$ $\mathrm{CaCO}_{3}$, converts to basic Calcium oxide $(\mathrm{CaO})$, and this is the cause for increased alkalinity ${ }^{(22)}$. Ten chicken eggs were obtained from the local industry (Cairo, Egypt). The chicken eggshell (CES) was cleaned with running water to remove any depress content and then was boiled in a hot water bath at temperature $100^{\circ} \mathrm{C}$ for about 10 minutes to facilitate the removal of its inner membrane. These ES 
then was crushed for about 5 minutes using a clean mortar and pestle to obtain small size crushed particles which heated in a muffle furnace at $1200^{\circ} \mathrm{C}$ (Thermolyne 48,000) for about 20 minutes followed by quenching and then was crushed again using a mortar and pestle for 5 minutes to obtain a powder with the relatively same size ${ }^{(18)}$.

\section{Preparation of Artificial Saliva:}

The artificial saliva was prepared via addition of $0.2 \mathrm{mM} \mathrm{MgCl}_{2}, 1 \mathrm{mM} \mathrm{CaCl}, 4 \mathrm{mM} \mathrm{Na}_{2} \mathrm{HPO}_{4}$, $16 \mathrm{mM} \mathrm{KCl}, 4.5 \mathrm{mM} \mathrm{NH}_{4} \mathrm{Cl}$ and $20 \mathrm{mM}$ HEPES (4-(2-hydroxyethyl) piperazine-1-ethane-sulfonic acid) buffer. The $\mathrm{pH}$ of the resulted solution was adjusted to 7.0 with $1 \mathrm{M} \mathrm{NaOH}$ and stored at $4{ }^{\circ} \mathrm{C}(24)$.

\section{Preparation of Remineralization Solutions:}

Five grams of CESP and Bioactive glass (Nano gate, Egypt) were dissolved in $100 \mathrm{ml}$ of distilled water in a graduated plastic container. These solutions were steered in magnetic stirrer for 3 minutes and then kept in the refrigerator until use ${ }^{(18)}$. For every 24 hours, freshly prepared solutions were used and the samples washed with distilled water before each successive immersion.

\section{Sample Collection and Preparation:}

Thirty caries-free, human premolars extracted for orthodontics purpose were collected and used in this study. The premolar's teeth were cleaned using distilled water and then decoronated at the cementoenamel junction (CEJ). Each crown was varnished with nail varnish at all surfaces except the buccal surface.

\section{Demineralization Procedure:}

Twenty-five premolars samples before storage and treatment were immersed in the demineralizing solution for 72 hours at $37^{\circ} \mathrm{C}$. The demineralization solution composed of (2.2 mM of $\mathrm{CaCl}_{2}$ (calcium chloride), $2.2 \mathrm{mM}$ of $\mathrm{NaH}_{2} \mathrm{PO}_{4}$ (monosodium phosphate), and $0.05 \mathrm{mM}$ of acetic acid having $\mathrm{pH}$ adjusted to 4.5 using $\mathrm{NaOH}$ (sodium hydroxide) to created sub-surface demineralization on the buccal surface of the premolar's samples ${ }^{(18,25)}$.

\section{Sample Grouping:}

All demineralized teeth samples were randomly divided into five groups $(n=5)$ according to the remineralizing solutions as follow:

Group I: Untreated group "control group”.

Group II: Subsurface demineralization only "demineralized group".

Group III: Subsurface demineralization followed by immersion in the CESP solution.

Group IV: Subsurface demineralization followed by immersion in BAG solution.

Group V: Subsurface demineralization followed by immersion in CESP/BAG solution (1:1).

Group VI: Subsurface demineralization followed by topical application of CPP-ACP (GC MI paste Plus ${ }^{\circledR}$, GC, USA).

Each group was immersed in $20 \mathrm{ml}$ of artificial saliva separately in a plastic graduated container for 21 days in the refrigerator. The samples of each group were daily removed from saliva and washed with distilled water before immersion in the remineralizing solutions or application of topical CPP-ACP for 2 minutes twice daily. The samples then were washed copiously again with distilled water before re-immersion in saliva.

\section{Surface Morphology and Remineralization Analysis}

The morphology and elemental chemical composition on the surface of the investigated samples were examined by scanning electron microscopy (SEM) coupled with energy dispersive X-ray (EDX) spectroscopy.

Energy dispersive x-ray (EDX) spectrometry (Module Oxford 6587 INCA x-sight) attached to scanning electron microscopy (SEM) at $20 \mathrm{KV}$, at the Regional Center of Mycology and Biotechnology (RCMB), Cairo, Egypt, were used to analyze 
the $\mathrm{Ca} / \mathrm{P}$ ratio in all samples. Enamel surface morphology was examined by scanning electron microscopy (SEM) (JEOL JSM-5500 LV, JEOL Ltd, Japan) by using a low vacuum mode after gold coating using SPI-Module sputter coater.

\section{Statistical Analysis}

All collected data were analyzed with One-way ANOVA followed by Tukey's test. Statistical analysis was done with SPSS version 23 software (IBM Corp., USA) with a significant level at $\mathrm{p} \leq 0.05$.

\section{RESULTS}

\section{Morphological analysis by SEM}

\section{Imaging of the demineralized enamel}

According to the image of SEM at low magnification of $500 \mathrm{X}$, the artificially demineralized enamel surface showed a discontinuous and broken enamel crystal (Figure 1B). It also revealed a cribriform-plates that might resemble the honeycomb-like profile of demineralized enamel at higher magnification due to the loss of minerals.

\section{Imaging of treated groups}

As shown in SEM images in (Figure 1) the surface of the treated samples revealed a lot of similarities, which exposed the effect of different treatment in enamel remineralization. The surface of all treated samples illustrated newly grown hydroxyapatite layers were formed on the demineralized enamel surface which indicates remineralization of demineralized enamel samples (Figure 1C-1F).

In (Figure 1C); CESP treated surfaces, appeared covered by a relatively uniform layer of newly formed hydroxyapatite crystals. However, enamel micro-cavities were filled with the newly formed minerals, but their borders were still visible. While, in (Figures 1D, 1E, and 1F); the enamel surface appeared covered by a more uniform, fine, and smooth layer of newly formed hydroxyapatite minerals.

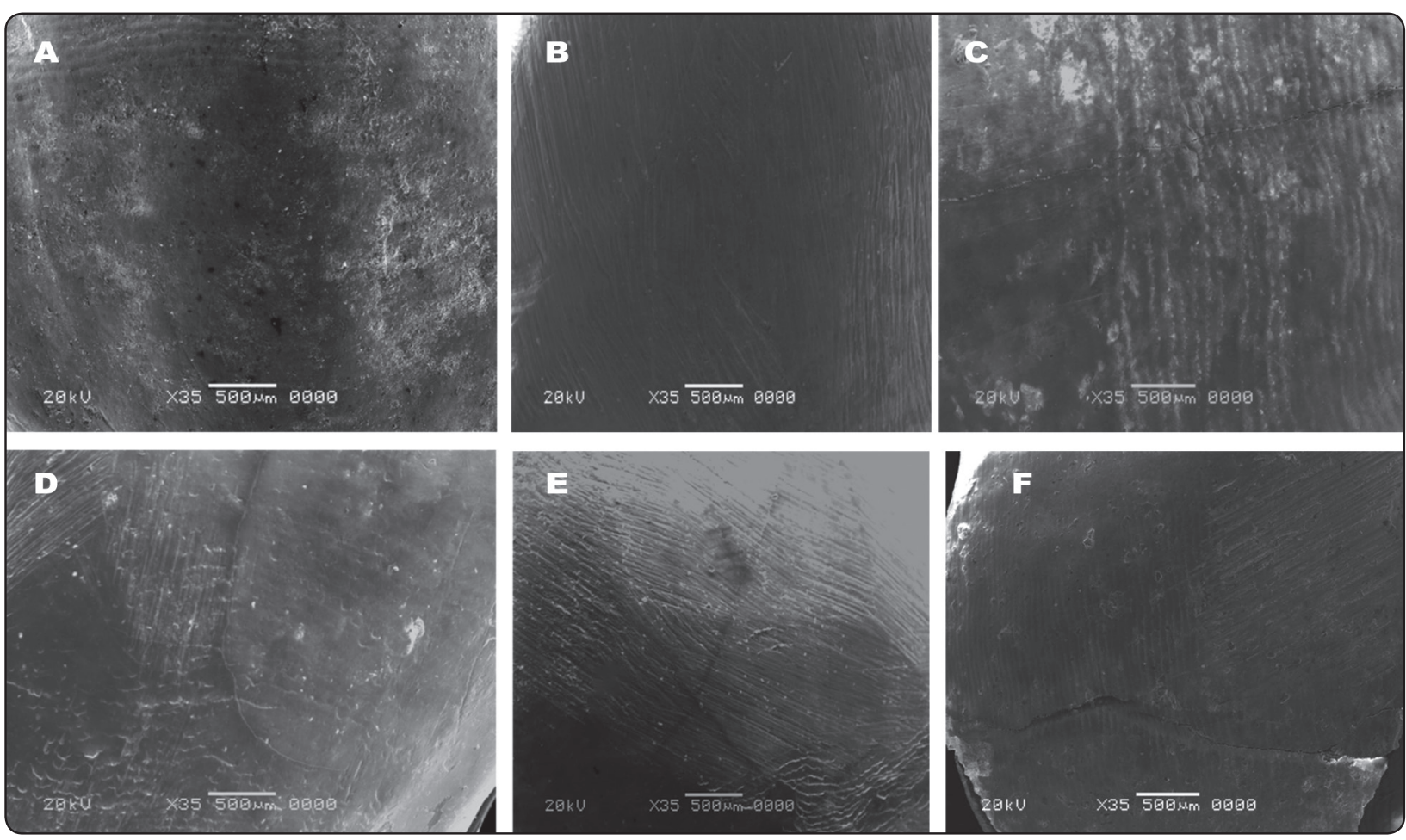

Fig. (1) SEM images of untreated enamel (1A), demineralized enamel (1B), CESP treated enamel (1C), BAG treated enamel (1D), CESP/BAG treated enamel (1E), and CPP-ACP treated enamel (1F). 


\section{Elemental chemical Analysis by EDX}

The results of EDX atomic analyses revealed that; the quantitative amounts of $\mathrm{Ca}$ atomic \% and $\mathrm{P}$ atomic \% was statistically greater for all the four treated groups when compared with the demineralized group. Although, there was no statistical difference among all treated groups which tested for elemental $\mathrm{Ca} \%$ and $\mathrm{P} \%$ atomic analysis. However, there was a statistically significant analysis in the $\mathrm{Ca} / \mathrm{P}$ ratio among all investigated groups (Table 1).

The demineralized group that treated with the CESP solution showed the highest $\mathrm{Ca} / \mathrm{P}$ ratio among all treated groups followed by the group that treated with BAG/CESP solution. While the demineralized group that treated with CPP-ACP showed the lower $\mathrm{Ca} / \mathrm{P}$ ratio among the all treated groups.

TABLE (1) $\mathrm{Ca} / \mathrm{P}$ ratio for all tested groups

\begin{tabular}{|l|l|l|l|}
\hline Group & $\mathbf{C a} \%$ & $\mathbf{P} \%$ & $\mathbf{C a} / \mathbf{P}$ ratio \\
\hline Group I (Control) & $72.87^{\mathrm{A}}$ & $27.13^{\mathrm{A}}$ & $2.68^{\mathrm{A}}$ \\
\hline Group II & $25.58^{\mathrm{B}}$ & $14.42^{\mathrm{B}}$ & $1.77^{\mathrm{B}}$ \\
\hline Group III & $70.39^{\mathrm{A}}$ & $29.61^{\mathrm{A}}$ & $2.37^{\mathrm{A}}$ \\
\hline Group IV & $65.69^{\mathrm{A}}$ & $34.31^{\mathrm{A}}$ & $1.94^{\mathrm{B}}$ \\
\hline Group V & $67.21^{\mathrm{A}}$ & $32.79^{\mathrm{A}}$ & $2.04^{\mathrm{B}}$ \\
\hline Group VI & $66.41^{\mathrm{A}}$ & $33.59^{\mathrm{A}}$ & $1.97^{\mathrm{B}}$ \\
\hline
\end{tabular}

*Different letters mean statistically significant

\section{DISCUSSION}

Enamel is the outer-most layer of the tooth, it should withstand a wide range of chemical changes namely; acid challenges from diet and plaque as well as physical changes that include abrasion, attrition, and compressive forces (up to $700 \mathrm{~N}$ ) during chewing ${ }^{(2,3)}$.

There was complex chemistry between diet, oral bacteria, and salivary components, which finally resulted in the dissolution of the carbonated hydroxyapatite mineral of the enamel during the process is known as demineralization ${ }^{(10)}$. If the demineralization process stands for a long time, the result will be loss of enamel minerals as well as the loss of enamel structure hence the tooth cavitation as the result ${ }^{(5)}$. The remineralization process has been studied for a long time to control the demineralization process and/or enhance the remineralization of enamel thus giving potential benefits for life-time oral health ${ }^{(26)}$.

Current traumatic treatments of early enamel carious lesions should be replaced with safe effective, and recent atraumatic remineralization treatment, especially at very early stages of enamel lesion ${ }^{(27,28)}$. It was found that the use of remineralizing agents as CESS, BAG, and CPP-ACP have a remarkable ability to enhance remineralization throughout all layers in initial caries-like enamel lesions invitro $^{(10,11,18)}$.

In this study, the selection of saliva as storage media to accommodate the oral conditions as well as because of the saliva is an important factor in the demineralization-remineralization cycle. As, when saliva becomes over-saturated with $\mathrm{Ca}$ and $\mathrm{HPO}_{4}$ ions, it contributes to the decrease of minerals content on the surface of enamel, that demineralized previously, and increases its resistance to the demineralization process ${ }^{(29,30)}$.

Also, it was found that the demineralization process resulted in subsurface lesions due to the deep penetration of acid ions leaving the surface intact. While, the remineralization process preferentially occurs at the enamel surface due to increase levels of calcium and phosphate ions, fluoride ions, and buffering by salivary products ${ }^{(18,25)}$.

In the present study, the concentration of both $\mathrm{Ca}$ and $\mathrm{HPO}_{4}$ ions in the demineralizing solution was at approximately $50 \%$ of saturation level, which caused only the dissolution of enamel for about 150 microns width with an intact surface to 
simulate an early enamel carious lesion ${ }^{(18,25)}$. While, the calcination process in a muffle is done to obtain pathogenic free, pure CESP as well as to increase its alkalinity ${ }^{(18,22)}$.

The results of the present study showed that; the use of CESS as a remineralizing agent was led to the formation of a relatively uniform layer of newly formed hydroxyapatite crystals as well as a higher $\mathrm{Ca} / \mathrm{P}$ ratio among the treated groups. This might be due to a very high percentage of bio-available calcium (about 95\% wt./wt.) in CESP, as the calcium plays an active and significant role in the remineralization process of enamel ${ }^{(18,31,32)}$.

BAG was considered as a huge step forward in enamel remineralization technology as it contains minerals that present naturally in oral fluids ${ }^{(12,33)}$. Also, it reacts when it comes to direct contact with saliva or water to release $\mathrm{Ca}, \mathrm{HPO}_{4}$, sodium $(\mathrm{Na})$, and silicon $(\mathrm{Si})$ ions hence it was able to form HAP crystals ${ }^{(10,33)}$.

It was found that the concentration of $\mathrm{Ca}$ ions in the remineralizing agent is a determinable factor in the remineralization process ${ }^{(10)}$. This can explain the result of this study; where the demineralized enamel group treated with CESS alone (Group III) showed a higher $\mathrm{Ca} / \mathrm{P}$ ratio than that treated with $\mathrm{BAG}$ alone or CESS/BAG (Group IV and V). Additionally, why the enamel that treated with CESS/BAG showed a higher $\mathrm{Ca} / \mathrm{P}$ ratio than that treated with $\mathrm{BAG}$ alone. This may be due to that the concentration of $\mathrm{Ca}$ ions in the BAG is about from $20 \%$ to $24.5 \%{ }^{(34,35)}$

Generally, during the manufacturing process of CPP-ACP; the calcium fluoride $(\mathrm{CaF})$, coexist in a protective-like barrier. This acts as a transporting media for tri-calcium phosphate to tooth enamel. When it came in contact with saliva during tooth brushing, the protective barrier will break and eventually makes $\mathrm{Ca}, \mathrm{HPO}_{4}$, and $\mathrm{F}$ ions readily available to the enamel. This was helpful in the termination of the demineralization process and promotes remineralization ${ }^{(22,36)}$.
According to the results of this study, it was found that; CPP-ACP with 900 ppm fluoride level, as claimed by the manufacturer shows the lesser remineralization effect in surface and subsurface carious-like lesions of enamel among all treated groups. This may be due to that, the concentration of the diffusible calcium in form of free $\mathrm{Ca}$ ions in CPP-ACP was about 5.0 to $9.0 \%$, while, the reminder $\mathrm{Ca}$ ions were in complex with $\mathrm{CPP}{ }^{(37)}$.

\section{CONCLUSIONS}

With the limitation of this in-vitro study, it was found that; the use of CESS, BAG, and CPP-ACP showed beneficial effect as a non-invasive treatment of early enamel lesion. However, CESS showed a significant improvement in the recovery of invitro carious like enamel lesion.

\section{REFERENCES}

1. Abdelmegid FY, Salama FS, Abouobaid EI, Halawany HS, Alhadlaq MK. Effect of Remineralizing Agents on Bond Strength of Resin-Composites to Primary Enamel. J Clin Pediatr Dent. 2019; 43:331-36.

2. Daas I, Badr S, Osman E. Comparison between Fluoride and Nano-hydroxyapatite in Remineralizing Initial Enamel Lesion: An in vitro Study. J Contemp Dent Pract. 2018; 19:306-12.

3. Gao Y, Liang K, Weir MD, Gao J, Imazato S, Tay FR, et al. Enamel remineralization via poly (amido amine) and adhesive resin containing calcium phosphate nanoparticles. J Dent. 2020; 92:103262.

4. Chandru TP, Yahiya MB, Peedikayil FC, Dhanesh N, Srikant N, Kottayi S. Comparative evaluation of three different toothpastes on remineralization potential of initial enamel lesions: A scanning electron microscopic study. Indian J Dent Res. 2020;31:217-23.

5. Farooq I, Bugshan A. The role of salivary contents and modern technologies in the remineralization of dental enamel: a narrative review. Version 2. F1000Res. 2020; 9:171-77.

6. Ajaj MT, Al-Khateeb SN, Al-Batayneh OB. Effect of different acid etchants on the remineralization process of white-spot lesions: An in vitro study. Am J Dent. 2020; 33:43-47. 
7. Huysmans MC, Chew HP, Ellwood RP. Clinical studies of dental erosion and erosive wear. Caries Res. 2011; 45: 60-68.

8. Behrouzi P, Heshmat H, Hoorizad Ganjkar M, Tabatabaei SF, Kharazifard MJ. Effect of Two Methods of Remineralization and Resin Infiltration on Surface Hardness of Artificially Induced Enamel Lesions. J Dent (Shiraz). 2020; 21:12-17.

9. Ma L, Chen J, Han H, Liu P, Wang H, Lin S, et al. Effects of lemon essential oil and limonene on the progress of early caries: An in vitro study. Arch Oral Biol. 2020; 111:104638.

10. Jindal S, Gupta N, Gupta P, Arora V, Mehta N. Reverse the Adverse: A Review. Int J Adv Health Sci. 2015; 1:21-24.

11. Elkassas D, Arafa A. Remineralizing efficacy of different calcium-phosphate and fluoride-based delivery vehicles on artificial caries like enamel lesions. J Dent. 2014; 42:466-74.

12. Taha AA, Fleming PS, Hill RG, Patel MP. Enamel Remineralization with Novel Bioactive Glass Air Abrasion. J Dent Res. 2018; 97:1438-44.

13. Aimutis WR. Bioactive properties of milk proteins with particular focus on anticariogenesis. J Nutr. 2004; 134: 989S-95S.

14. Arifa MK, Ephraim R, Rajamani T. Recent Advances in Dental Hard Tissue Remineralization: A Review of Literature. Int J Clin Pediatr Dent. 2019; 12: 139-44.

15. Hemagaran G. Remineralization of the tooth structure - the future of dentistry. Int J PharmTech Res. 2014; 6:487-93.

16. Walsh LJ. Contemporary technologies for remineralization therapies: a review. Int Dent. 2009; 11:6-16.

17. Prestes L, Souza BM. In situ effect of chewing gum containing CPP-ACP on the mineral precipitation of eroded bovine enamel: a surface hardness analysis. J Denti. 2013; 41:747-51.

18. Mony B, Ebenezar AVR, Ghani MF, Nnarayanan A, Anand S, Mohan AG. Effect of Chicken Egg Shell Powder Solution on Early Enamel Carious Lesions: An Invitro Preliminary Study. J Clin Diag Res. 2015; 9: ZC30-ZC32.

19. Carounanidy U, Sathyanarayanan R. Dental caries: A complete changeover, Part III: Changeover in the treatment decisions and treatments. J Conserv Dent. 2010; 13:209-17.
20. Vashisht R, Indira R, Ramachandran S, Kumar A, Srinivasan MR. Role of casein phosphopeptide amorphous calcium phosphate in remineralization of white spot lesions and inhibition of Streptococcus mutans. J Conserv Dent. 2013; 16:342-46.

21. Rezvani MB, Karimi M, Rasoolzade R A, Haghgoo R. Comparing the Effects of Whey Extract and Casein Phosphopeptide-Amorphous Calcium Phosphate (CPP-ACP) on Enamel Microhardness. J Dent Shiraz Univ Med Sci. 2015; 16: 49-53.

22. Shen P, Manton DJ, Cochrane NJ, Walker GD, Yuan Y, Reynolds C, et al. Effect of added calcium phosphate on enamel remineralization by fluoride in a randomized controlled in situ trial. J Dent. 2011; 39:518-25.

23. Methods of producing egg shell powder: Patents: US 20060062857 A1.

24. Zaharia A, Plescan VG, Atkinson I, Mocioiu OC, Cantaragiu A, Musat V. Remineralization of natural tooth enamel in artificial saliva environment. REV.CHIM. (Bucharest).2017;68: 510-14.

25. Lata S, Varghese NO, Varughese JM. Remineralization potential of fluoride and amorphous calcium phosphatecasein phosphopeptide on enamel lesions: An in vitro comparative evaluation. J Conserv Dent. 2010; 13:42-46.

26. Shen P, Walker GD, Yuan Y, Reynolds C, Stanton DP, Fernando JR, et al. Importance of bioavailable calcium in fluoride dentifrices for enamel remineralization. J Dent. 2018; 78:59-64.

27. Fernández-Ferrer L, Vicente-Ruíz M, García-Sanz V, Montiel-Company JM, Paredes-Gallardo V, Almerich-Silla JM, et al. Enamel remineralization therapies for treating postorthodontic white-spot lesions: A systematic review. J Am Dent Assoc. 2018; 149:778-86.

28. Sahin F, Oznurhan F. Antibacterial efficacy and remineralization capacity of glycyrrhizic acid added casein phosphopeptide-amorphous calcium phosphate. Microsc Res Tech. 2020. doi: 10.1002/jemt.23465.

29. Hicks J, Garcia-Godoy F, Flaitz C. Biological factors in dental caries: role of saliva and dental plaque in the dynamic process of demineralization and remineralization (part 1). J Clin Pediatr Dent. 2003; 28:47-52.

30. Bossù $M$, Saccucci $M$, Salucci $A$, Di Giorgio G, Bruni E, Uccelletti D, et al. Enamel remineralization and repair results of Biomimetic Hydroxyapatite toothpaste on deciduous teeth: an effective option to fluoride toothpaste. J Nanobiotechnol. 2019; 17: 1-13. 
31. Schaafsma A, van Doormaal JJ, Muskiet FA, Hofstede GJ, Pakan I, van der Veer E. Positive effects of a chicken eggshell powder-enriched vitamin-mineral supplement on femoral neck bone mineral density in healthy late postmenopausal Dutch women. Br J Nutr. 2002; 87:267-75.

32. Rovenský J, Stancíková M, Masaryk P, Svík K, Istok R. Eggshell calcium in the prevention and treatment of osteoporosis. Int J Clin Pharmacol Res. 2003; 23:83-92.

33. Pandya M, Diekwisch TGH. Enamel biomimetics-fiction or future of dentistry. Int J Oral Sci. 2019; 11:8-10.

34. Karasu B, Yanar AO, Koçak A, Kısacık Ö. Bioactive glasses. ECJSE. 2017; 4:436-71.
35. Memarpour M, Shafiei F, Rafiee A, Soltani M, Dashti MH. Effect of hydroxyapatite nanoparticles on enamel remineralization and estimation of fissure sealant bond strength to remineralized tooth surfaces: an in vitro study. BMC Oral Health. 2019; 19:92-96.

36. Thierens LAM, Moerman S, Van Elst C, Vercruysse C, Maes $\mathrm{P}$, Temmerman $\mathrm{L}$, et al. The in vitro remineralizing effect of CPP-ACP and CPP-ACPF after 6 and 12 weeks on initial caries lesion. J Appl Oral Sci 2019; 27:1-9.

37. Zeitouny M, Fayyad-Kazan H, Tassery H, Fayyad-Kazan H. In Vitro Influence of Prophylaxis Cleaning on Enamel Remineralization with Casein Phosphopeptide-Amorphous Calcium Phosphate. J Oral Maxillofac Res. 2020;11: e4. 